\title{
Hemoglobin Hasharon in a Premature Infant with Hemolytic Anemia
}

\author{
RODNEY L. LEVINE, DAVID R. LINCOLN, WILLIAM M. BUCHHOLZ, T. JOHN GRIBBLE, \\ AND HERBERT C. SCHWARTZ ${ }^{(33)}$ \\ Department of Pediatrics, Stanford Medical School, Stanford, California, and Department of \\ Biochemistry, University of Oregon School of Medicine, Portland, Oregon, USA
}

\section{Extract}

A premature infant with jaundice was found to have a compensated hemolytic process as evidenced by mild hyperbilirubinemia, a regenerative anemia, and persistence for several months of reticulocytosis, polychromatophilia, and stippled macrocytes. There was no blood loss. When hemoglobins from this family were electrophoresed, the propositus and her mother were found to be heterozygous for an abnormal hemoglobin. The variant hemoglobin, which was $20 \%$ of the mother's hemoglobin, had the electrophoretic mobility of hemoglobin S; however, sickle preparations were negative at $24 \mathrm{hr}$ and, in contrast to hemoglobin $\mathrm{S}$, the hemoglobin was soluble in $2.58 \mathrm{M}$ phosphate buffer. The mother's pattern also revealed a faint band running behind $A_{2}$ and very close to the origin. The distance between this variant and $A_{2}$ was about the same as the distance between the major variant and $A$. Such a pattern suggested that the hemoglobin mutation was in the $\alpha$ chain. Examination of the infant's electrophoretic pattern revealed a third variant hemoglobin whose distance from fetal hemoglobin was the same as the distances of the variants in the mother's pattern, which indicated that an abnormal fetal hemoglobin was present. By 7 months of age the infant's electrophoretic pattern was identical with that of her mother and the variant hemoglobin accounted for about $20 \%$ of the total.

Since the propositus was a premature infant, structural studies were carried out on the adult variant which was isolated chromatographically from the mother's blood. Analysis of the tryptic peptide chromatogram of the $\alpha$ chain revealed that peptide T- 6 was absent; a new peptide was isolated at a lower position on the chromatogram. The amino acid composition of this peptide revealed that the aspartic acid at position 47 was replaced by histidine. Therefore, the mutant hemoglobin was hemoglobin Hasharon ( $\alpha-47$ (CD5) aspartic acid $\rightarrow$ histidine).

Chromatographically prepared hemoglobin $\mathrm{F}$ was hybridized with a similar preparation of the adult hemoglobin Hasharon. After electrophoresis, we found bands corresponding to hemoglobin A and to the fetal hemoglobin Hasharon, as well as the original hemoglobin $\mathbf{F}$ and adult hemoglobin Hasharon. There were also two bands which migrated anodal to hemoglobin A which might have been hemoglobin $\mathbf{H}$ and hemoglobin Bart's, representing tetramers of the normal $\beta$ and $\gamma$ chains. These tetramers may have formed because of the relative instability of the mutant $\alpha$ chains.

\section{Speculation}

The marked hemolytic process in this premature infant was dependent on the presence of the fetal form of hemoglobin Hasharon in fetal erythrocytes. Hemolysis resolved as these cells were replaced by adult-type erythrocytes which contained the adult form of hemoglobin Hasharon.
Most hereditary hemolytic anemias caused by an abnormal hemoglobin are due to mutations in the $\beta$ chain of hemoglobin. Since the rate of $\beta$ chain synthesis is relatively low at birth, $\beta$ chain hemoglobinopathies such as sickle cell anemia are rarely present clinically in the immediate neonatal period. This report concerns a premature infant with hemolytic anemia associated with an $\alpha$ chain mutation. The variant was identified as hemoglobin Hasharon, in which the aspartic acid at the 47 th residue of the $\alpha$ chain is replaced by histidine (7). The hematologic picture among adults who are heterozygous for hemoglobin Hasharon is quite variable. Although adults $(3,4,7,26,29)$ are generally without symptoms, Charache et al. (4) described a 70-year-old heterozygote who had a mild hemolytic anemia. Two other, apparently normal, newborn infants have been found previously to be carriers of hemoglobin Hasharon through cord blood screening programs $(7,26)$. The hemolytic process in the premature infant reported here may have resulted from the presence of the fetal form of hemoglobin Hasharon in fetal erythrocytes. An older infant with hemoglobin Hasharon and a hemolytic anemia has been reported previously (28).

\section{CASE REPORT}

The propositus was a 965-g female born in September 1971 at 30 weeks' gestation to a 29 -year-old gravida 4 mother. Pregnancy had been uncomplicated until membranes ruptured 4 days before delivery. The infant was transferred to Stanford University Hospital because of prematurity and risk of infection from the premature rupture of membranes. The mother had given birth previously to a term male in 1963 and had delivered a male of 26 weeks' gestation who died with hyaline membrane disease in 1967. A molar pregnancy was terminated by dilatation and curretage in 1965.

The infant's mother was of Italian, English, and Filipino descent and the father was of Cherokee Indian and Irish stock. There was no family history of jaundice, bleeding disorders, or splenectomy. An 11-year-old niece was anemic and had a peptic ulcer.

On initial physical examination the propositus was mildly jaundiced, but there was no pallor or hepatosplenomegaly. There were occasional episodes of apnea during the first few weeks of life which responded to stimulation. During this period the infant was placed occasionally in oxygen concentrations up to $30 \%$ in an effort to decrease the frequency of apneic episodes. Her clinical course was otherwise unremarkable.

She received a course of penicillin and kanamycin because of the premature rupture of membranes. However, there was no significant growth in multiple cultures of blood, urine, cerebrospinal fluid, and tracheal aspirate, or in maternal amniotic fluid and membranes.

Admission laboratory data at age 2 days revealed a hemoglobin of $14.6 \mathrm{~g} / 100 \mathrm{ml}$, a packed cell volume of $41.7 \%$, 
a reticulocyte count of $19.4 \%$, and a white blood count of $32,000 / \mathrm{mm}^{3}$ with a differential of $68 \%$ segmented neutrophils, $9 \%$ bands, $21 \%$ lymphocytes, and $2 \%$ monocytes. The peripheral smear showed evidence of a hemolytic process with marked anisocytosis and poikilocytosis, polychromatophilia, stippling, and fragmentation of erythrocytes. The bilirubin was $9.0 \mathrm{mg} / 100 \mathrm{ml}$. It rose to a maximum of $11.9 \mathrm{mg} / 100 \mathrm{ml}$ on the third day of life, and gradually fell to normal values by 4 weeks of age. The direct Coombs test was negative. Both the mother and infant were type $\mathrm{A}, \mathrm{Rh}^{+}$. No blood loss was observed clinically.

Medications administered during the hospitalization were as follows: penicillin, 100,000 U/ kg/24 hr im, and kanamycin, 15 $\mathrm{mg} / \mathrm{kg} / 24 \mathrm{hr}$ im, from days 2 through 6 ; calcium gluconate, 50 $\mathrm{mg}$ iv on day 3; phytonadione, $0.25 \mathrm{mg}$ im on day 5; ferrous sulfate, $5 \mathrm{mg}$ elemental iron daily; a vitamin A, C, and D supplement (Tri-Vi-Sol), $0.2 \mathrm{ml}$ daily; and sodium bicarbonate, $2 \mathrm{mEq} / \mathrm{kg} / 24 \mathrm{hr}$ orally from days 18 to 30 . Serum vitamin E, as determined by Dr. D. Melhorn, Cleveland, Ohio (17), was $0.30 \mathrm{mg} / 100 \mathrm{ml}$ on day 50 . The infant was given $50 \mathrm{mg}$ vitamin $\mathrm{E}(\alpha$-tocopherol acetate) im on day 53 and $5.0 \mathrm{mg}$ daily beginning on day 60 . There was no response to this therapy.

During her hospitalization, the baby gained weight in accordance with normal premature standards. Her discharge weight was $2,075 \mathrm{~g}$ at age 63 days, which corresponds to a postmenstrual age of 39 weeks. She was clinically well at 7 months of age, at which time her hemoglobin was $12.0 \mathrm{~g} / 100$ $\mathrm{ml}$, packed cell volume $34.5 \%$, and reticulocyte count $3.3 \%$.

\section{MATERIALS AND METHODS}

Fresh blood was collected with EDTA as anticoagulant. Heinz body preparations were made with $0.5 \%$ methyl violet in normal saline. Thermolabile hemoglobin was tested by the method of Dacie et al. (5) in 0.1 M Tris buffer, pH 7.4, at $50^{\circ}$. Glucose 6-phosphate dehydrogenase activity was determined by the method of Motulsky (19). Electrophoresis was performed on starch gels at $\mathrm{pH} 8.3$ in Tris-EDTA-borate buffer. The proportions of the hemoglobins were determined by starch block electrophoresis using Veronal buffer, $\mathrm{pH} 8.6$ $(14,15)$. Alkali-resistant hemoglobin was determined with standard techniques $(14,27)$.

Hemolysates were prepared by the addition of water and toluene to packed erythrocytes which had been washed three times with isotonic saline. The adult form of hemoglobin Hasharon was chromatographically prepared on an IRC column $(14,25)$. The hemolysate was first dialyzed against Developer 6; the same solution was employed to pre-equilibrate the column. Eight milliliters of a $10 \mathrm{~g} / 100 \mathrm{ml}$ solution of hemoglobin was placed on the column $(1.2$ by $30 \mathrm{~cm})$. The column was rinsed with the same developer. Hemoglobin was eluted with a $150 \mathrm{mM}$ sodium phosphate buffer, $\mathrm{pH} 6.37$. Hemoglobin A eluted before hemoglobin Hasharon. The abnormal hemoglobin fraction was vacuum concentrated and its purity confirmed by starch gel electrophoresis.

For identification of the amino acid substitution in this abnormal hemoglobin, the hemolysate was first centrifuged at $20,000 \times g$ for $30 \mathrm{~min}$. The supernatant solution was dialyzed against starting buffer and then subjected to chromatography on DEAE-Sephadex for isolation of the abnormal hemoglobin (9). Structural analyses were performed by preparation of aminoethylated $\alpha$ chains from globin, column chromatography of the tryptic peptides, and amino acid analyses of the peptides $(13,26)$.

Hybridization of hemoglobin Hasharon with chromatographically prepared hemoglobin $\mathrm{F}$ was performed according to published methods $(6,12)$. The control consisted of a simple mixture of the two hemoglobins which was set aside and stored at $4^{\circ}$. Aliquots of the hybridized mixture and of the control were subjected to starch gel electrophoresis at $\mathrm{pH}$ 8.6 .

\section{RESULTS}

\section{INITIAL STUDIES}

The variation in hemoglobin and reticulocyte count is plotted in Figure 1. The hemoglobin fell from an initial value of $15.4 \mathrm{~g} / 100 \mathrm{ml}$ to 10 at 2 weeks of age and to a nadir of 8.5 at 4 weeks of age. The reticulocyte count was about $20 \%$ during the first 5 weeks. During the period of elevated reticulocyte count, the peripheral smear continued to show anisocytosis, poikilocytosis, polychromatophilia, and fragmentation of erythrocytes. As the reticulocyte count fell and the hemoglobin rose, the morphology of the erythrocytes gradually approached normal. By 15 weeks of age, there was only minimal anisocytosis. The total serum bilirubin was 9.0 $\mathrm{mg} / 100 \mathrm{ml}$ on admission and rose to a high of $11.9 \mathrm{mg} / 100 \mathrm{ml}$ $24 \mathrm{hr}$ after admission. At 11 days of age the bilirubin was 4.1 $\mathrm{mg} / 100 \mathrm{ml}$ and at 4 weeks of age it was $1.5 \mathrm{mg} / 100 \mathrm{ml}$.

The peripheral smears of both parents and the brother were unremarkable. Their hemoglobin concentrations, reticulocyte counts, and bilirubin concentrations were normal.

Wet Heinz body preparations on the infant's blood were negative on two occasions. Glucose 6-phosphate dehydrogenase activity was normal (decolorization in $37 \mathrm{~min}$; normal adults, 40-60 min). No thermolabile hemoglobin was detected when tested at $50^{\circ}$.

When hemoglobins from this family were electrophoresed, an abnormal pattern was found in the propositus and her mother (Fig. 2). The mother had a variant hemoglobin with the electrophoretic mobility of hemoglobin S. However, sickle preparations were negative at $24 \mathrm{hr}$, and the hemoglobin was soluble in $2.58 \mathrm{M}$ phosphate buffer, in contrast to hemoglobin $\mathrm{S}$ (11). The mother's pattern also revealed a faint band running behind $\mathrm{A}_{2}$ and very close to the origin. The distance between this variant and $\mathrm{A}_{2}$ was about the same as the distance between the major variant and A. Such a pattern suggested that the hemoglobin mutation was in the $\alpha$ chain. Examination of the infant's electrophoretic pattern revealed a third variant hemoglobin whose distance from fetal hemoglobin was the same as the distances of the variants in the mother's pattern.

Fetal forms of $\alpha$ chain variants are generally alkali resistant (18). At 8 weeks of age this infant had $75 \%$ alkali-resistant

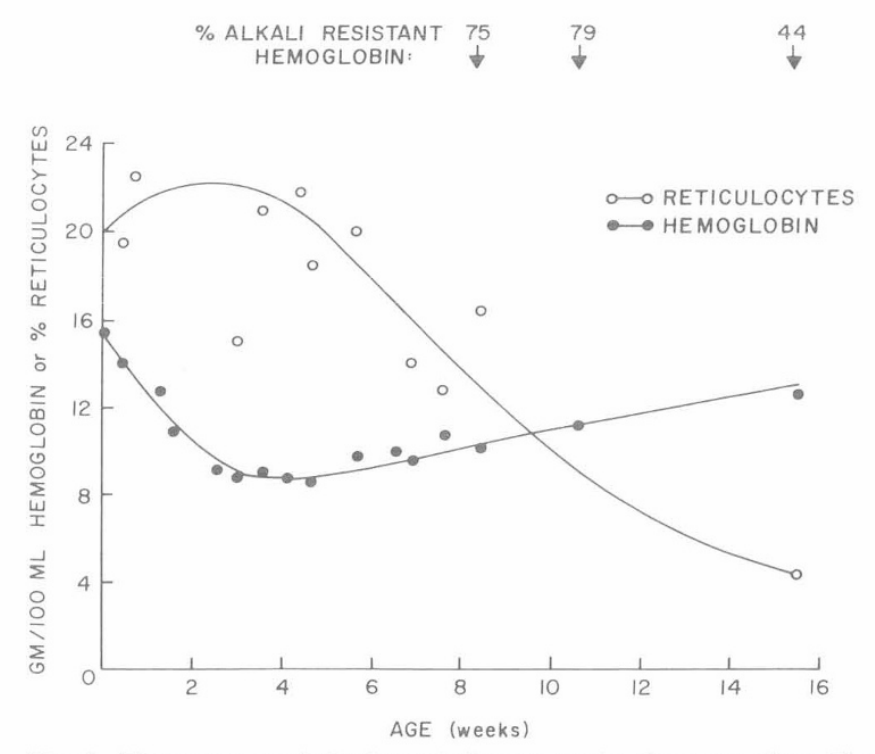

Fig. 1. Time course of the hemolytic process in the propositus. The percentage of alkali-resistant hemoglobin is shown at the top of the figure. 


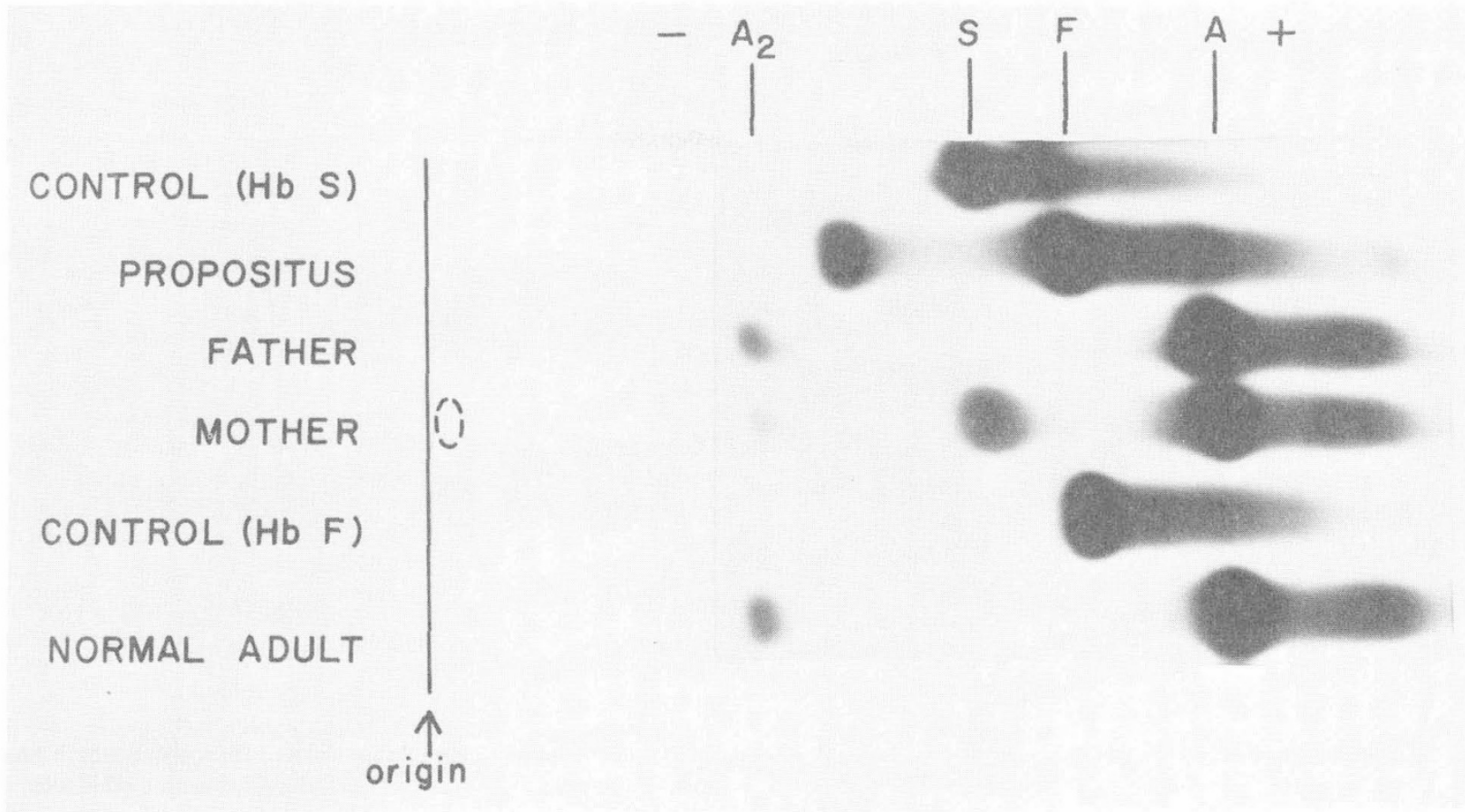

Fig. 2. Electrophoretic pattern of hemoglobin $(\mathrm{Hb})$ from the propositus and her family. The propositus was 38 days of age at this time. The positions of control hemoglobins are indicated at the top of the figure. The position of a faint band near the origin in the mother's pattern has been indicated by a dashed ellipse.

hemoglobin. At 11 weeks it was $79 \%$, and at 15 weeks of age was $44 \%$. The electrophoretic pattern at 15 weeks showed an obvious increase in hemoglobin A. It was also between 11 and 15 weeks of age that the blood smear became normal. By 7 months of age the infant's electrophoretic pattern was identical with that of her mother. At this time the variant hemoglobin accounted for about $20 \%$ of the total in both mother and propositus (Table 1).

\section{IDENTIFICATION OF MUTATION}

Since the propositus was a small premature infant, structural studies were carried out on the adult variant which was isolated chromatographically from the mother's blood. Analysis of the tryptic peptide chromatogram of the $\alpha$ chain revealed that peptide T- 6 was absent; a new peptide was isolated at a lower position on the chromatogram. The amino acid composition of this peptide corresponded to that of the T-6 peptide from normal hemoglobin A except for the absence of aspartic acid and the presence of an additional residue of histidine. The normal T-6 peptide contains only one aspartic acid residue, at position 47 (CD5). Therefore the mutant hemoglobin was hemoglobin Hasharon, in which the aspartic acid at position 47 was replaced by histidine. This hemoglobin had been described previously in at least five other families, all of whom were of Jewish descent $(3,7,26,28,29)$. There were no known Jewish ancestors in this family.

\section{HYBRIDIZATION EXPERIMENT}

Chromatographically prepared hemoglobin F was hybridized with a similar preparation of the adult hemoglobin Hasharon. Figure 3 shows the resulting electrophoretic pattern. In addition to the original hemoglobin $\mathrm{F}$ and adult hemoglobin Hasharon, one finds bands corresponding to hemoglobin A and to the fetal hemoglobin Hasharon, as expected. There are also two bands migrating anodal to hemoglobin A which may be hemoglobin $\mathrm{H}$ and hemoglobin Bart's, representing the tetramers of the normal $\beta$ and $\gamma$ chains. These tetramers may have formed because of the relative instability of the mutant $\alpha$ chains (see Discussion). One cannot quantitate the amounts of
Table 1. Distribution of hemoglobins

\begin{tabular}{lccc}
\hline \multicolumn{1}{c}{ Subject } & A, \% & Hasharon, $\%$ & $\mathrm{~A}_{\mathbf{2}}, \%$ \\
\hline Propositus (age 7 mo) & 78.8 & 18.1 & 3.1 \\
Mother & 76.9 & 20.1 & 3.0 \\
Father & 97.2 & & 2.8 \\
Brother (age 9 yr) & 96.7 & & 3.3 \\
Control & 96.3 & & 3.7 \\
\hline
\end{tabular}

each hemoglobin species present in Figure 3, but it is clear that the normal hemoglobins $\mathrm{A}$ and $\mathrm{F}$ are present in greater quantity than the Hasharon forms of $\mathrm{A}$ and $\mathrm{F}$.

\section{DISCUSSION}

When $a$ chain variants of hemoglobin occur, they are present in significant concentrations at birth (18). This contrasts with $\beta$ chain variants such as hemoglobin $S$ which become quantitatively significant as $\beta$ chain synthesis replaces $\gamma$ chain production during the first months after birth. We have described a premature infant with a regenerative anemia and jaundice who was heterozygous for the $\alpha$ chain hemoglobin variant, hemoglobin Hasharon. The mild hyperbilirubinemia, anemia, and persistence for several months of reticulocytosis, polychromatophilia, and stippled macrocytes suggested in the absence of blood loss that a compensated hemolytic process existed. Two newborn infants heterozygous for hemoglobin Hasharon have been previousıy reported $(7,26)$. Their clinical and hematologic picture was not remarkable; however, they were found as part of a cord blood screening program and mild hemolysis might not have been detected. An older infant has been reported with hemoglobin Hasharon, a hemolytic anemia, and splenomegaly (28). Although the abnormal hemoglobin was inherited from the father, the hemolytic process may have been due in part to "an unknown red cell defect perhaps inherited from the mother" who had "a slight increase in bilirubin $(1.3 \mathrm{mg} / 100 \mathrm{ml})$, a decreased haptoglobin (below 75 $\mathrm{mg} / 100 \mathrm{ml})$, and a reticulocytosis of $3 \%$." 


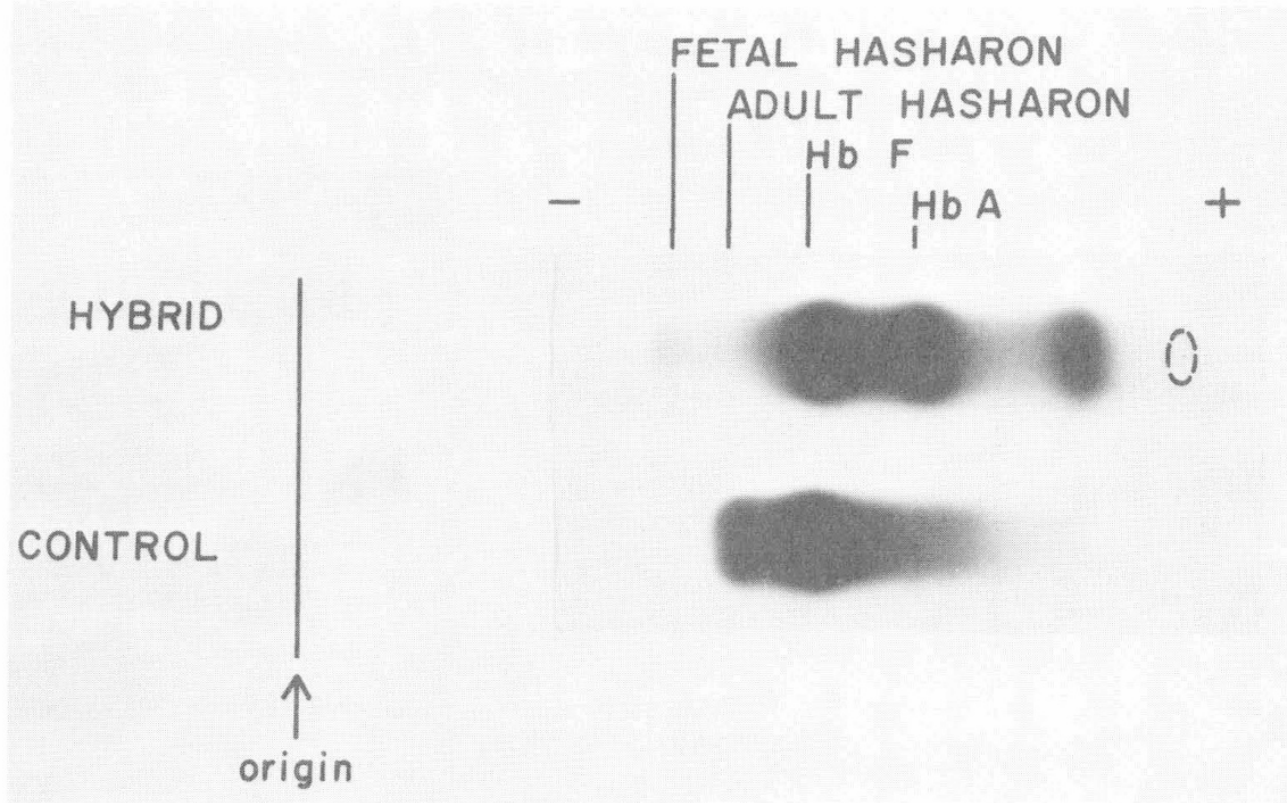

Fig. 3. Electrophoretic pattern of the hybridization of hemoglobin $\mathrm{F}(\mathrm{Hb} \mathrm{F})$ and the variant hemoglobin isolated from the mother's blood. The control is a simple mixture of these two hemoglobins. The position of a rapidly migrating, faint band in the hybrid has been outlined by a dashed ellipse.

Hemoglobin Hasharon varies in its clinical manifestations. Adult heterozygotes are usually asymptomatic and have normal hematologic values $(4,7,26,29)$. However, Charache et al. (4) described a 70-year-old heterozygote who had splenomegaly, gallstones, and a hemolytic anemia with a reticulocyte count of $5 \%$. Study of that patient's family revealed that 9 of 24 persons were carriers but "Hematocrit values, morphological characteristics of red cells, and fetal hemoglobin levels were normal in all family members." Nevertheless, reticulocyte counts were slightly increased in family members who were carriers as compared with noncarriers $(2.5 \%$ versus $1.3 \%$, which is statistically significant with $P$ less than 0.01 ). Although autohemolysis and incubated Heinz body preparations were normal, denaturation of hemoglobin Hasharon was greatly increased over hemoglobin A at $60^{\circ}$ or $65^{\circ}$, indicating that hemoglobin Hasharon was less stable than hemoglobin A.

Variability in clinical presentation also occurs with hemoglobin Beilinson in which the aspartic acid at $\alpha-47$ is changed to glycine (21). Residue 47 is located on the surface of the hemoglobin molecule and is not directly involved in the formation of the heme pocket nor in the $\alpha-\beta$ chain contact points (20). However, the detailed quaternary structure of fetal hemoglobin has not yet been determined. With present knowledge one cannot present a convincing molecular explanation for the instability of either the adult or fetal forms of hemoglobin Hasharon (for detailed reviews, see References 10 and 24).

One can suggest several explanations for the resolution of the marked hemolysis observed in this premature infant. These include the following: (1) decreased stability of the fetal hemoglobin Hasharon compared with the adult hemoglobin Hasharon; (2) decreased stability within the environment of the fetal erythrocyte; and (3) or change in the rate of synthesis of the variant hemoglobins.

\section{DECREASED STABILITY OF THE FETAL HEMOGLOBIN HASHARON}

Hemoglobin can dissociate into globin subunits. These subunits are much more susceptible to denaturation than is native hemoglobin (10). The unstable mutant hemoglobins have a greater tendency to dissociate into subunits, and this increased dissociation leads to hemolysis in the unstable hemolytic anemias (2). It is also known that hemoglobin $\mathrm{F}$ is less stable than hemoglobin A $(1,2,16)$, presumably as a result of the 10 -fold greater affinity between $\alpha$ and $\beta$ chains compared with $\alpha$ and $\gamma$ chains (8). The interaction of Hasharon $\alpha$ chains with normal $\beta$ chains must be only minimally decreased (4). However, the interaction of Hasharon $\alpha$ chains with $\gamma$ chains would be considerably less. Thus the fetal form of hemoglobin Hasharon may be much less stable than the adult form. Such instability could cause hemolytic anemia in this premature infant in whom $80 \%$ of the total hemoglobin was fetal type.

\section{DECREASED STABILITY WITHIN FETAL ERYTHROCYTE}

Differences in hemolysis might be a result of the peculiar environment or structure of the fetal erythrocyte itself. Fetal erythrocytes containing either the fetal or adult forms of hemoglobin Hasharon may be more prone to hemolysis than adult erythrocytes. There are many distinct chemical and metabolic differences between fetal and adult erythrocytes which may contribute to the increased susceptibility of fetal cells $(22,23)$. As discussed above, heat denaturation experiments have demonstrated a subtle decrease in the stability of hemoglobin Hasharon (4); the results of the hybridization experiment (Fig. 3) may also be explained by this decreased stability. A minimal decrease in hemoglobin stability may be insignificant in the adult erythrocyte, but of great import in the fetal erythrocyte. The time course of the hemolytic process in our patient (Fig. 1) is consistent with such an explanation.

\section{CHANGE IN RATE OF SYNTHESIS OF VARIANT CHAIN}

As noted in our two heterozygotes, hemoglobin Hasharon usually comprises about $20 \%$ of the total hemoglobin (4). Either decreased synthesis or increased destruction or a combination of both could account for this lower than $50 \%$ concentration. Charache et al. (4) showed that heterozygotes synthesize only $20-27 \%$ of their hemoglobin as Hasharon, which demonstrated that decreased synthesis determines the 
proportion of Hasharon in heterozygotes. The genetics of the $\alpha$ chain are unclear at present (30). It may be that there are two loci for the $\alpha$ chain; this could account for the presence of $20-25 \% \alpha$ chain mutants instead of the $50 \%$ which might be expected if there were only a single locus. The rate of synthesis of mutant $\alpha$ chains could change if transcription from these two loci may be varied independently.

Knowing that the adult form of hemoglobin Hasharon is less stable than hemoglobin A, Charache et al. (4) suggested that overt hemolytic anemia might result if the synthesis of hemoglobin Hasharon were increased. It may be that the hemolysis which occurred in our patient was due to an increased rate of synthesis of the mutant $\alpha$ chain, and that hemolysis resolved as the rate of synthesis of the mutant decreased to adult levels.

\section{SUMMARY}

A premature infant with a hemolytic anemia was found to be heterozygous for hemoglobin Hasharon ( $\alpha-47$ (CD5) aspartic acid $\rightarrow$ histidine), an $\alpha$ chain variant. The hemolysis resolved during the period in which fetal erythrocytes containing the fetal form of the variant hemoglobin were replaced by adult erythrocytes containing the adult form of the variant hemoglobin. By 7 months of age the infant's electrophoretic pattern was identical with that of her mother, who was also a carrier of the variant. The hemolytic anemia in this infant is in contrast to adults with hemoglobin Hasharon who are general clinically unremarkable.

\section{REFERENCES AND NOTES}

1. Betke, K.: Vergleichende untersuchung der oxydation von fetalem und Erwachsenen-Oxyhämoglobin durch Natriumnitrit. Naturwissenschaften, 40: 60 (1953).

2. Carrell, R. W., and Lehmann, H.: The unstable haemoglobin haemolytic anaemias. Semin. Hematol., 6: 116 (1969).

3. Charache, S., and Mondzac, A. M.: Hemoglobin Sinai $\left(\alpha_{2}{ }^{47}\right.$ His $\beta_{2}$ ): An unstable hemoglobin causing occult hemolysis. Blood, 30: 879 (1967).

4. Charache, S., Mondzac, A. M., and Gessner, U.: Hemoglobin Hasharon $\left(\alpha_{2}{ }^{47} \mathrm{His}(\mathrm{CD} 5) \beta_{2}\right)$ : A hemoglobin found in low concentration. J. Clin. Invest., 48: 834 (1969).

5. Dacie, J. V., Grimes, A. J., Meisler, A., Steingold, L., Hemsted, E. H., Beaven, G. H., and White, J. C.: Hereditary Heinz-body anaemia. Brit. J. Haematol., 10: 388 (1964).

6. Gammack, D. B., Huehns, E. R., Shooter, E. M., and Gerald, P. S.: Identification of the abnormal polypeptide chain of haemoglobin $\mathrm{G}_{\mathrm{Ib}}$. J. Mol. Biol., 2: 372 (1960).

7. Halbrecht, I., Issacs, W. A., Lehmann, H., and Ben-Porat, F. Hemoglobin Hasharon (47 aspartic acid $\rightarrow$ histidine). Isr. J. Med. Sci., 3: 827 (1967).

8. Huehns, E. R., Beaven, G. H., and Stevens, B. L.: Reaction of haemoglobin $a^{\mathrm{A}}$ with haemoglobins $\beta_{4}{ }^{\mathrm{A}}, \quad \gamma_{4}{ }^{\mathrm{F}}$ and $\delta_{2}$, Biochem. J., 92: 444 (1964).

9. Huisman, T. H. J., and Dozy, A. M.: Studies on the heterogeneity of hemoglobin. IX. The use of tris(hydroxymethyl)amninomethane- $\mathrm{HCl}$ buffers in the anion-exchange chromatography of hemoglobins, J. Chromatogr., 19: 160 (1965).

10. Huisman, T. H. J., and Schroeder, W. A.: Alteration in the properties of human hemoglobin $\mathrm{A}$ by variation in structure: $\mathrm{A}$ correlation of structure and function. C. R. C. Rev. Clin. Lab. Sci., 1: 473 (1970).

11. Itano, H. A.: Solubilities of naturally occuring mixtures of human hemoglobin. Arch. Biochem. Biophys., 47: 148 (1953).

12. Itano, H. A., and Robinson, E.: Formation of normal and doubly abnormal haemoglobins by recombination of haemoglobin I with
S and C. Nature, 183: 1799 (1959).

13. Jones, R. T.: Automatic peptide chromatography. Methods Biochem. Anal, 18: 205 (1970).

14. Jonxis, J. H. P., and Huisman, T. H. J.: A Laboratory Manual on Abnormal Hemoglobins (Blackwell Scientific Publications, Oxford, 1968).

15. Kunkel, H. G., and Wallenius, G.: New hemoglobin in normal adult blood. Science, 122: 288 (1955)

16. Lecks, H. I.: Methemoglobinemia in infancy. Amer. J. Dis. Child., 79: 117 (1950).

17. Melhorn, D. K., and Gross, S.: Vitamin E-dependent anemia in the premature infant. I. Effects of large doses of medicinal iron. J. Pediat., 79: 569 (1971)

18. Minnich, V., Cordonnier, J. K., Williams, W. J., and Moore, C. V.: Alpha, beta, and gamma hemoglobin polypeptide chains during the neonatal period with a description of a fetal form of hemoglobin D $\mathrm{St}$. Louis. Blood, 19: 137 (1962).

19. Motulsky, A. G.: Population genetics of glucose-6-phosphate dehydrogenase deficiency of the red cell. In: B. S. Blumberg. Proceedings of the Conference on Genetic Polymorphisms and Geographic Variations in Disease (Grune and Stratton, New York, N. Y., 1961).

20. Muirhead, H., Cox, J. M., Mazzarella, L., and Perutz, M. F.: Structure and function of haemoglobin. III. A three dimensional Fourier synthesis of human deoxyhaemoglobin at $5.5 \AA$ resolution. J. Mol. Biol., 28: 117 (1967).

21. Nagel, R. L., Ranney, H. M., Bradley, T. B., Jacobs, A., and Udem, L.: Hemoglobin L Ferrara in a Jewish family associated with a hemolytic state in the propositus. Blood, 34: 157 (1969).

22. Oski, F. A.: The unique fetal red cell and its function. Pediatrics, 51: 494 (1973).

23. Oski, F. A., and Naiman, J. L.: Hematologic Problems in the Newborn, Ed. 2, pp. 83-132 (W. B. Saunders, Philadelphia, 1972).

24. Perutz, M. F., and Lehmann, H.: Molecular pathology of human haemoglobin. Nature, 219: 902 (1968).

25. Schnek, A. G., and Schroeder, W. A.: The relation between the minor components of whole normal human adult hemoglobin as isolated by chromatography and starch block electrophoresis. J. Amer. Chem. Soc., 83: 1472 (1961).

26. Schneider, R. G., Ueda, S., Alperin, J. B., Brimhall, B., and Jones, R. T.: Hemoglobin Sealy $\left(\alpha_{2}{ }^{4} 7 \mathrm{His}_{2}\right)$ : A new variant in a Jewish family. Amer. J. Hum. Genet., 20: 151 (1968).

27. Singer, K., Chernoff, A. I., and Singer, L.: Studies on abnormal hemoglobins. I. Their demonstration in sickle cell anemia and other hematologic disorders by means of alkali denaturation. Blood, 6: 413 (1951)

28. Tatsis, B., Dosik, H., Rieder, R., and Lee, S. L.: Hemoglobin Hasharon: Severe hemolytic anemia and hypersplenism associated with a mildly unstable hemoglobin. In: D. Bergsma: Birth Defects: Original Article Series, Vol. VIII, pp. 25-28 (The Williams and Wilkins Co., Baltimore, 1972).

29. Vella, F., Eng, A. C., and Merry, C. C.: An $\alpha$ TpVI hemoglobin variant in Manitoba. Clin. Biochem., 3: 125 (1970).

30. Wasi, P.: Is the human globin $\alpha$-chain locus duplicated? Brit. J. Haematol, 24: 267 (1973).

31. Informed consent was obtained from the mother and father.

32. We thank Dr. R. T. Jones for valuable advice and Ms. Diana Edmunds for expert technical assistance. These studies were supported in part by Grants nos. AM 12467, AM 13173, GM 01200 , HD 00049, HD 02147, and RR-81 from the Genera Clinical Research Centers Program of the Division of Research Sources, National Institutes of Health. Dr. T. J. Gribble was a Dernham Senior Fellow of the American Cancer Society, California Division (D-169) and Dr. R: L. Levine was a Predoctoral Fellow of the Medical Scientist Training Program under Grant no. GM-1922 from the National Institutes of Health. Computer support was provided by the Advanced Computer for Medical Research (ACME) Facility at Stanford Medical Center, with support through grant RR-00311 from the National Institutes of Health.

33. Requests for reprints should be addressed to: H. C. Schwartz, M.D., Department of Pediatrics, Stanford Medical Center, Stanford, California 94305 (USA).

34. Accepted for publication May 21, 1974. 